\title{
Research Article \\ Buckling of Imperfect Thin Cylindrical Shell under Lateral Pressure
}

\author{
R. Lo Frano and G. Forasassi \\ Department of Mechanical, Nuclear and Production Engineering, University of Pisa, Via Diotisalvi 2, 56126 Pisa, Italy
}

Correspondence should be addressed to R. Lo Frano, rosa.lofrano@ing.unipi.it

Received 21 June 2007; Accepted 7 February 2008

Recommended by Siegfried Langenbuch

The strength of thin shells, under external pressure, is highly dependent by the nature of imperfection. This paper investigates buckling behaviour of imperfect thin cylindrical shells with analytical, numerical, and experimental methods in conditions for which, at present, a complete theoretical analysis was not found in literature. In general, collapse is initiated by yielding, but interaction with geometrical instabilities is meaningful, in that imperfections reduce the load bearing capacity by an amount of engineering significance also when thickness is considerable. The aim of this study was to conduct experiments that are representative of buckling, in the context of NPP applications as, for instance, the IRIS (international reactor innovative and secure) and LWR steam generator (SG) tubes. At Pisa University, a research activity is being carried out on the buckling of thin walled metal specimen, with a test equipment (and the necessary data acquisition facility) as well as numerical models were set up by means FEM code. The experiments were conducted on A-316 test specimens, tubes with and without longitudinal welding. The numerical and experimental results comparison highlighted the influence of different types of imperfections on the buckling loads with a good agreement between the finite-element predictions and the experimental data.

Copyright (C) 2008 R. Lo Frano and G. Forasassi. This is an open access article distributed under the Creative Commons Attribution License, which permits unrestricted use, distribution, and reproduction in any medium, provided the original work is properly cited.

\section{INTRODUCTION}

The stability of circular cylindrical shells under uniform lateral pressure has been widely investigated. The behavior of cylindrical shells under external pressure is very sensitive to geometric imperfections. There have been many theoretical studies investigating the strength of cylinders with specific imperfection forms, and it is well established that axisymmetric imperfections cause the greatest reductions in strength [1]. Many researchers have studied buckling of circular cylindrical shell under external pressure and more accurate solutions of the present problem were obtained for short cylindrical shells and for anisotropic shells, respectively. However, actual calculations seem to be confined mainly to some special ranges of the shells geometries, boundary, and loading conditions [2].

Moreover, the literature concerning unequal wall transition joints in thin shell is limited. When thin shells were subjected to external pressure, the collapse was initiated by yielding, which was often the dominant factor but the interaction with the instability is meaningful. In fact, the presence of im- perfections reduces the load bearing capacity by an amount of engineering significance; so the classical elastic solution, like [3], appears to be not adequate.

The major factors that affected the collapse pressure of pipes were the diameter-to-thickness ratio $D / t$, the Young's modulus and yield stress of the material in the circumferential direction, and initial imperfections in the form of ovality and wall thickness variations $[4,5]$, as for eccentricity and presence of welding joint.

The current paper examined the buckling issue of a thin circular cylindrical shell in the dimension range of possible interest for the nuclear steam generator (SG) of type foresee in the IRIS Reactor. IRIS is currently under way of preliminary design; it was an integral pressurized water reactor. Its reactor pressure vessel houses not only the nuclear core, but also all the major reactor primary coolant system components such as pumps, steam generators, pressurizer, control rod drive mechanisms, and neutron reflector.

The IRIS integral vessel is larger than a traditional PWR pressure vessel, but the size of the IRIS containment results to be smaller than that of corresponding loop reactors, resulting 
in a significant reduction in the overall size of the reactor plant [6]. The IRIS SGs were once through, with the primary fluid outside the tubes.

In general, buckling analysis is used to predict failure of long pipelines, subjected to external over pressure.

A selected configuration was used to perform the different analysis significant for the specified field of interests (numerical as well as experimental).

The present study might also serve as a base for other loading models, which include different boundary and geometrical conditions. Buckling phenomenon occurs when most of the strain energy, which is stored as membrane energy, can be converted to the bending energy requiring large deflections.

Nonlinear buckling pressures can be evaluated using a nonlinear stress analysis by observing the first change in the slope (i.e., stiffness of the structure) in the load-deflection curve $[7,8]$. In the nonlinear buckling analysis; however, an initial imperfection, either in terms of the geometry or load, is necessary to trigger the buckling phenomenon. The load carrying capacity of shell subjected to an external pressure could be characterized by the yield load. The first yield load was not considered as a failure pressure, because it was no equivalent to an immediate loss of stability.

\section{THEORETICAL ANALYSIS}

Elastic structures can buckle under excessive loads. In order to determine whether a given structure can become unstable or not, a first step is to apply a linear stability analysis. A linear stability analysis using the normal-mode approach always results in an eigenvalue problem, the solution of which gives a bifurcation condition.

The classical analytical approach is based on the classic elastic solution like Donnel or Flugge theories. Among these, Donnel's theory represents a general approach, while that of Flugge is considered to be more refined than the linear Donnell-type stability one. From the Donnell stability equations in uncoupled form [9], adopting an analytical procedure of minimization, one can obtain the critical pressure load in the simplified form

$$
\begin{aligned}
& \bar{p}=\frac{\left(1+\overline{n^{2}}\right)^{2}}{\overline{n^{2}}}+\frac{1}{\overline{n^{2}}\left(1+\overline{n^{2}}\right)^{2}} \frac{12}{\pi^{4}} Z^{2}, \\
& Z=\frac{L^{2}}{(R h)}\left(1-v^{2}\right)^{0.5},
\end{aligned}
$$

where $v$ is Poisson's ratio; $h R$ and $L$ are thickness, the radius and length of the shell; $Z$ are the Batdorf parameter and $n$ is the number of circumferential waves.

The above formula of (1) is function of the single geometric parameter $Z$, known as Batford parameter.

Results of this procedure for large values of $Z$ or $L$ (long cylinder) are inaccurate because the associated membrane stiffness component includes a nonnegligible error.

Flugge's stability equation in coupled form the numerical solution is based on the exact solution of three differential Flugge's equations [10]. They describe the buckling of cylin- drical shell under the most general homogeneous membrane stress action. The numerical calculation leads to a solution, which describes a buckling mode with $\mathrm{n}$ half waves along the length of cylinder and $2 \mathrm{~m}$ half waves around its circumference. In perfect agreement with the asymptotic value for long shell, the simplified critical load is expressed as follows:

$$
\begin{aligned}
& q_{1}=\frac{\left(1-v^{2}\right) \lambda^{2}+k \lambda^{4}\left(\lambda^{2}+2(2-v)\right)}{\lambda^{2}-1}, \\
& q_{1}=\frac{p a}{D},
\end{aligned}
$$

where $k=h^{2} / 12 a^{2}$ is a dimensionless parameters; $h$ and $a$ are thickness and radius of the shell; $D$ is the bending stiffness, $p$ is the lateral pressure, while $\lambda=n \pi a / 1$ is a modal parameter, function of the radius $(a)$, the circumferential wave number $(n)$ and length of shell.

Of course also in this approach, if the cylinder is very long, its central part is little influenced by the stiffening effect of the bulkheads.

Among the analysed theories before, that of Cheng and Ho represents a general one, based on a very accurate Flugge's theory, which is considered to be more refined than the linear Donnell-type stability theory. Their analysis is rather lengthy; considerable numerical manipulation is required to obtain the critical load. This approach allows to obtain the simplified minimum value of buckling load for moderatelength cylinders [11]:

$$
P_{\text {cr }}=\frac{2 \pi E t^{2}}{3 \sqrt{6}\left(1-v^{2}\right)^{3 / 4} R L} \sqrt{\frac{t}{R}},
$$

where $v$ is Poisson's ratio; $t, L$, and $R$ are thickness, length, and radius of the shell; $E$ is Young's modulus. It may be observed that for a certain range of $L / R$, the calculations from the approximate formula of (3) are very close with the general buckling condition.

The resulting buckling pressures, determined for a thin shell of AISI 316, according to the above mentioned theories, are represented in Table 1 , for a wide range of geometries (characterized by the diameter and thickness) and for the same length equal to $828 \mathrm{~mm}$, and plotted in Figure 1. The material pressure-length curve is modelled by a multilinear curve to show the influence of geometrical parameters on studied theories. Results seem to indicate that linear theories are inadequate to predict real behavior in the presence of the imperfections.

\section{NUMERICAL ANALYSIS}

The presence of imperfections, such as the ovality, the eccentricity, or the variation of the thickness, due to presence of longitudinal welding, makes elastic analysis inadequate to the purpose of determining the critical load, so a nonlinear analysis was required. In this paper, nonlinear analysis was performed using a numerical analysis, in which either load or displacement was used as a control parameter. 
TABLE 1: Analytical values of pressure load.

\begin{tabular}{lcccr}
\hline$D$ & $t$ & Flugge theory $(\mathrm{Pa})$ & Donnel theory $(\mathrm{Pa})$ & Cheng Ho theory $(\mathrm{Pa})$ \\
\hline 15 & 1.2 & $2.59 \mathrm{E}+7$ & $3.15 \mathrm{E}+8$ & $1.70 \mathrm{E}+7$ \\
16 & 1.2 & $2.764 \mathrm{E}+7$ & $2.47 \mathrm{E}+8$ & $1.545 \mathrm{E}+7$ \\
17 & 1.5 & $3.67 \mathrm{E}+7$ & $4.03 \mathrm{E}+8$ & $2.46 \mathrm{E}+7$ \\
19 & 1.2 & $3.28 \mathrm{E}+7$ & $1.48 \mathrm{E}+8$ & $1.19 \mathrm{E}+7$ \\
20 & 1.5 & $4.32 \mathrm{E}+7$ & $2.23 \mathrm{E}+8$ & $1.93 \mathrm{E}+7$ \\
20 & 2 & $5.76 \mathrm{E}+7$ & $5.87 \mathrm{E}+8$ & $1.05 \mathrm{E}+7$ \\
30 & 1.2 & $5.18 \mathrm{E}+7$ & $3.76 \mathrm{E}+7$ & $1.11 \mathrm{E}+7$ \\
\hline
\end{tabular}

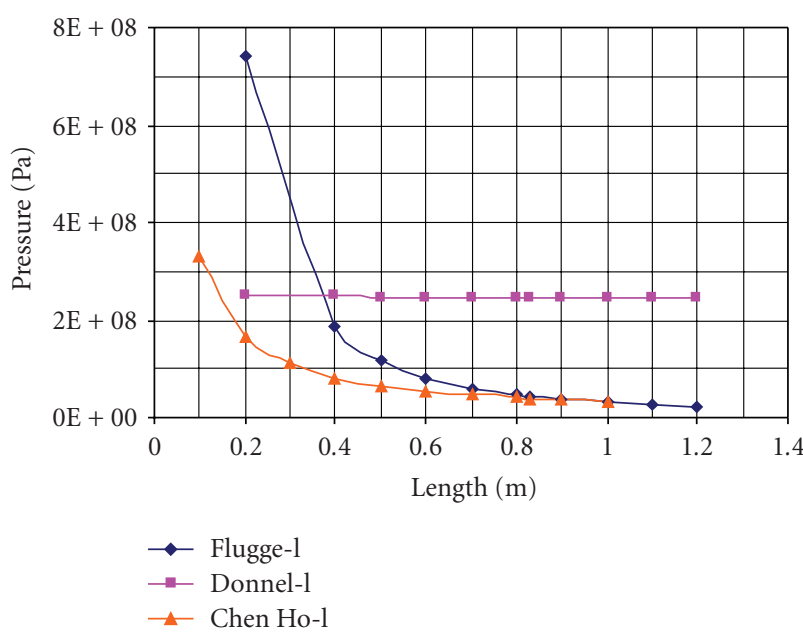

FIGURE 1: Linear analyses pressure results comparison.

This paper would address in the first case, the effect of imperfections, such as ovality or eccentricity, on buckling load, and in the second one the effect of a welded joint presence, which involves unequal wall thickness transition, on the strength of structure. Some different elastic-plastic buckling analyses were carried out by means of the finite element program MSC.MARC to evaluate the failure behavior of the transition joint and the effects of geometry. The assumption of perfect plasticity permitted a better assessment of the effects of circumferential instability. The tube was a long cylindrical shell of length $L$, uniform thickness $t$, diameter $D$; the two ends were assumed as fixed hedges, under simultaneous action of external lateral pressure.

In such cases, the models were realized with solid 3D finite elements. The cylindrical surface was modeled by use of 20-node brick elements, because shell elements were not adequate to compute the contribution of radial compression. The adopted mesh involved 60 elements over the circumferential section, and 5 elements on the thickness; moreover, the mesh in the case of transition welded joint was more refined in the welded area. In the numerical analyses, a nonlinear approach was adopted.

In fact, three different imperfections were considered: the eccentricity $(e)$, the ovality $(W)$, which is known to have the most detrimental effect on tube collapse, and the longitudinal welding. The imperfection parameters are defined as

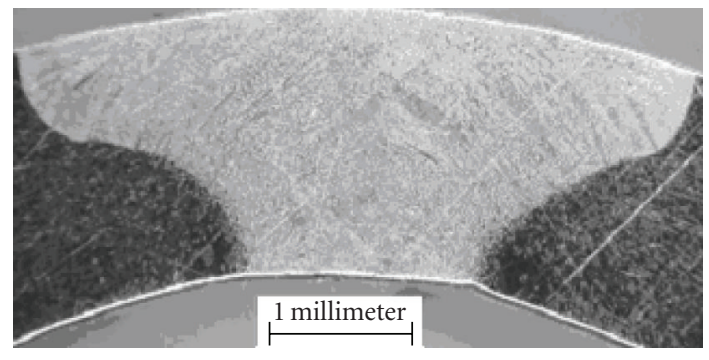

FIGURE 2: View of the welded joint in the section tube.

follows:

$$
\begin{gathered}
W=\frac{D_{\max }-D_{\min }}{D}, \\
e=\frac{t_{\max }-t_{\min }}{t_{\min }},
\end{gathered}
$$

where $D_{\max }$ and $D_{\min }$ are the maximum and minimum tube's diameter, while $D$ is the nominal diameter. In the same matter, $t_{\max }$ and $t_{\min }$ are the maximum and minimum tube's thickness.

The welding joint is characterized by a local thickness variation: a ridge occurred along the longitudinal welding [12]. The width variation of welded joint covers a range between 1.5 and about 4 millimetres on the inner and outer diameters. A view of the welded joint, in one section tube, is plotted in Figure 2.

Moreover, the analyses of section's tube by means of scanning electron microscope have highlighted the presence of a skeleton metallographic microstructure, in the weld joint quite different from the material alone shown in Figure 3.

Probably, this alteration induced by welding process might increase the local strength of tube. Therefore, this phenomenon was treated, in the numerical analysis, assuming the presence of these two areas with different stiffness.

Material properties, also, have been experimentally verified by means of tensile and Vickers tests. The tensile tests results, that were carried out to verify the material properties certification and that it may observe in the stressstrain curves (Figure 4), have confirmed the certified material properties, in the case of seamless A 316 tubes, while the recorded yielding stress values are greater than that certified (250 MPa) for welded specimen tube A 316. 


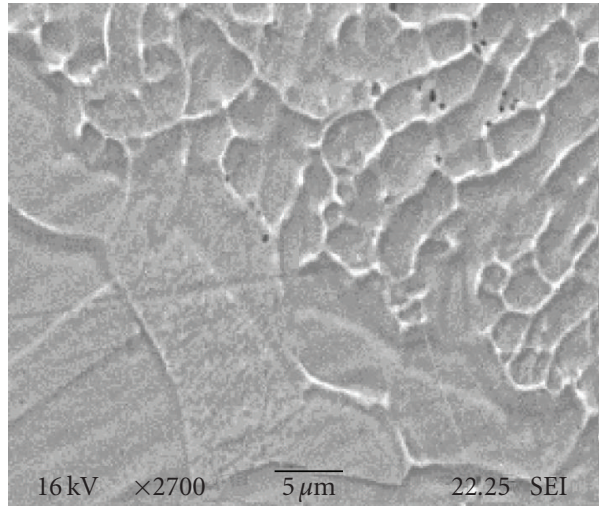

FIGURE 3: Details of transition area between welded joints.

In fact, tensile and Vickers tests have confirmed the alteration induced by the welding process which must be treated, in numerical analysis, assuming the presence of two areas with different stiffness, that is the welded area and the other tube part (see also in the sketched Figure 3).

Weld-induced residual stresses are usually discontinuous at the weld in a transition joint and can be significant in pipeline [13].

However, appropriate simulation has indicated that the differences of the failure pressure at plastic collapse were not noticeable with or without weld residual stress, thus this local effect, in the present analysis, was not considered.

The imperfections considered were of $20 \%$ of tube thickness for the eccentricity; $2.5 \%$ of nominal diameter for the ovality, while a thickness reduction of $12.5 \%$ (from the certified tolerance) was considered in the weld joint.

In the hypotheses of cylindrical shell in a bendingless state, before buckling, and of homogeneous external pressure, the critical load for long thin shell was performed adopting the equation;

$$
\begin{aligned}
& \frac{D}{h} \nabla^{8} \omega+E k_{x}^{2} \frac{\partial^{4} \omega}{\partial y^{4}}+2 E k_{x} k_{y} \frac{\partial^{4} \omega}{\partial x^{2} \partial y^{2}}+E k_{y}^{2} \frac{\partial^{4} \omega}{\partial x^{4}} \\
&-\sigma_{x}^{(0)} \nabla^{4}\left(\frac{\partial^{2} \omega}{\partial x^{2}}\right)-2 \sigma_{x y}^{(0)} \nabla^{4}\left(\frac{\partial^{2} \omega}{\partial x \partial y}\right)-\sigma_{y}^{(0)} \nabla^{4}\left(\frac{\partial^{2} \omega}{\partial y^{2}}\right)=0
\end{aligned}
$$

where $\sigma_{x}^{(0)}, \sigma_{x y}^{(0)}, \sigma_{y}^{(0)}$ are the initial membrane stresses; $\omega$ is the buckling deflection in the $z$ direction; $E$ is Young's modulus, $v$ is Poisson's ratio; $h$ and $L$ are the thickness and the length of the shell; $D=E h^{3} /\left[12\left(1-v^{2}\right)\right]$ is the bending stiffness; $k_{x} k_{y}$ were the curvatures in $x, y$ direction [14].

The boundary and load conditions were the same (real) ones, adopted for the experimental buckling tests on the AISI 316 tube.

Rigorous tolerance criteria for equilibrium iterations were applied and the size of increment was automatically determined according to the number of iterations in the previous increments. Mesh sizing used has demonstrated that is suitable to assure the convergence of results and to accurately predict collapse behavior. The deepening of the initial buckle was either a result of a local buckling process, characterized by a local instability, and/or of progressive stress-deflection dependence.

However, the reaching of a certain depth of the initial on going buckle can lead to the formation of another adjacent buckle if the material local resistance is larger than the local deformation one.

To quantify the effect of the imperfection parameters and the influence of the geometry on the load bearing behavior, shells of a wide range of diameters and thickness were investigated.

The influence of mentioned imperfections on the buckling loads is indicated for a wide range of geometries and assuming the same tube length equal to $828 \mathrm{~mm}$ in Table 2. In this table, there are overviews of the obtained buckling loads for perfect and for imperfect shells.

It is evident that the capacity of bearing load decreases in presence of important imperfections, such as the ovality and eccentricity, while the presence of a longitudinal material alteration, due to the welding, seems to have the opposite effect.

The eccentricity and the ovality have shown the most detrimental effect on tube collapse, while the longitudinal welding seems to induce positive stiffening effect due to the material and mechanic characteristics of the welded joint areas.

The deformed shapes of the thin cylindrical shells, for the cases of ovality, eccentricity, and welding joint imperfections, as for a selected $D / t$ ratio $(D / t=13.3)$ are shown in Figures 5,6 , and 7 as obtained in the first numerical analyses.

The displayed graphs and the numerical results point out that collapse load level is strictly dependent from imperfection; so the level of the first instability load initially falls with increasing imperfection amplitudes.

The number of waves around the circumference decreases as the length increases and takes the minimum value of two only for very long tubes $(L / R \geq 50)$.

\section{EXPERIMENTAL DEVICE}

The experiments were conducted on commercially available stainless steel AISI 316 tube specimens with nominal diameters of $20 \mathrm{~mm}$ and nominal thickness of $1.5 \mathrm{~mm}$. For a better explanation, type $\mathrm{A}$ and $\mathrm{B}$, in Table 3 , indicates specimens with and without welding joint.

The tests specimens were cut, from the own certified piece, to the corresponding length of $828 \mathrm{~mm}$. Firstly, the diameter $(D)$ has been measured at twelve equidistant points along the meridional length. This type of measure has been repeated along two equally spaced points on the same circumference, for type A as well as for those B.

Measured values of external diameter are in agreement with the nominal diameter for each test specimen. In fact, the small variations registered on the test specimens allowed to evaluate that the real mean ovality is about the $0.3 \%$, while the thickness mean variation measured around the transition joint is about the $10 \%$. A schematic diagram of the hydraulic pressure device and the specimen's support are represented in Figure 8. 


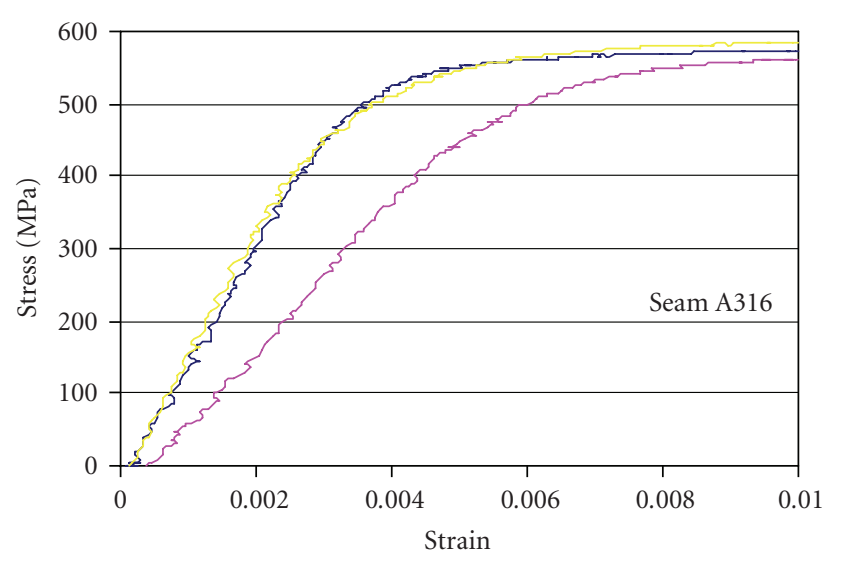

(a)

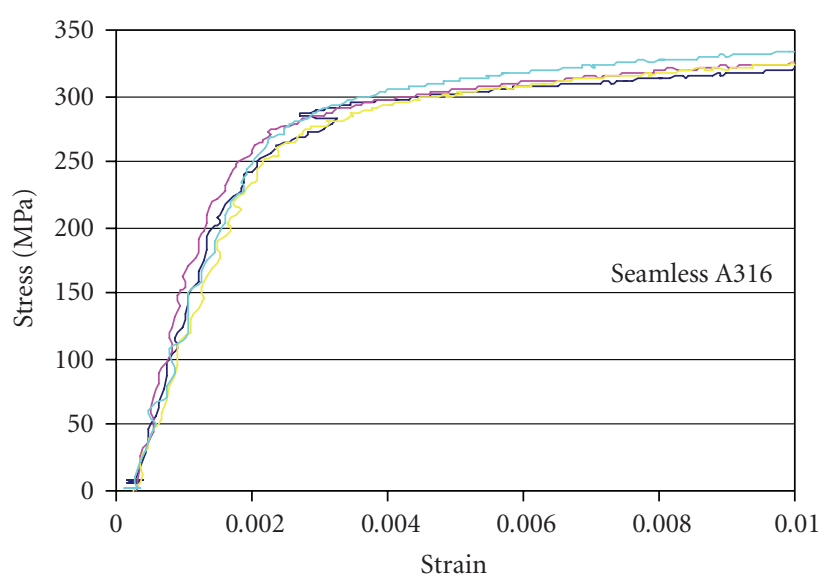

(b)

FIgURE 4: Diagrams stress versus strain.

TABLE 2: Buckling loads for perfect and imperfect shells.

\begin{tabular}{|c|c|c|c|c|c|}
\hline \multirow{2}{*}{$D(\mathrm{~mm})$} & \multirow{2}{*}{$t(\mathrm{~mm})$} & \multicolumn{4}{|c|}{ Buckling load $(\mathrm{Pa})$} \\
\hline & & Perfect shell & Eccentricity & Ovality & Weld joint \\
\hline 15 & 1.2 & $3.117 \mathrm{E}+7$ & $3.053 \mathrm{E}+7$ & $2.840 \mathrm{E}+7$ & $3.210 \mathrm{E}+7$ \\
\hline 16 & 1.2 & $3.370 \mathrm{E}+7$ & $3.316 \mathrm{E}+7$ & $3.277 \mathrm{E}+7$ & $3.373 \mathrm{E}+7$ \\
\hline 17 & 1.5 & $4.307 \mathrm{E}+7$ & $4.230 \mathrm{E}+7$ & $4.102 \mathrm{E}+7$ & $4.418 \mathrm{E}+7$ \\
\hline 19 & 1.2 & $4.127 \mathrm{E}+7$ & $4.074 \mathrm{E}+7$ & $3.958 \mathrm{E}+7$ & $4.215 \mathrm{E}+7$ \\
\hline 20 & 1.5 & $5.015 \mathrm{E}+7$ & $4.620 \mathrm{E}+7$ & $4.249 \mathrm{E}+7$ & $5.306 \mathrm{E}+7$ \\
\hline 20 & 2 & $5.691 \mathrm{E}+7$ & $5.248 \mathrm{E}+7$ & $5.375 \mathrm{E}+7$ & $6.507 \mathrm{E}+7$ \\
\hline 30 & 1.2 & $6.182 \mathrm{E}+7$ & $5.714 \mathrm{E}+7$ & $5.227 \mathrm{E}+7$ & $6.514 \mathrm{E}+7$ \\
\hline
\end{tabular}

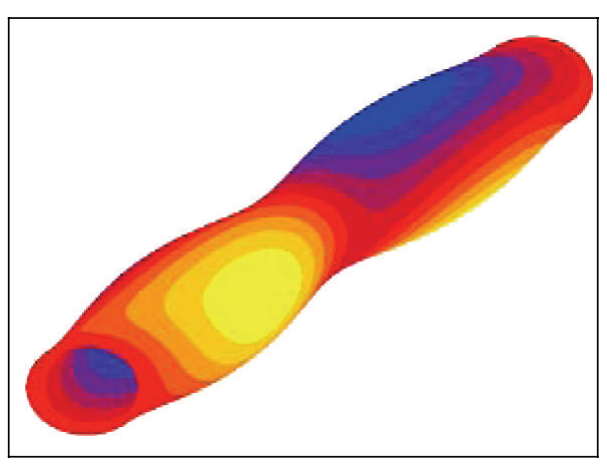

FIGURE 5: Deformed shape for shell with ovality.

These supports maintain the tube in the vertical position, so any rotations or preloaded states on the specimens, during the stages of the assembling, are prevented.

The test specimen was confined between two rigid cylindrical sliding base supports, manufactured in the laboratory of Pisa University .

Buckling tests adopted the same boundary conditions, end restraints, geometric properties, and load acting on the tube, used in all the numerical simulations. The required load and the strain relationship are recorded for each test and used later to check the numerical buckling results.



FIgURE 6: Deformed shape for shell with eccentricity.

Data acquisition system was based on strain gauge instrumentation, which allows recording the shell deformation.

A piezoelectric pressure transducer was used to measure the pressure in the test chamber, filled with oil, in which the test specimen and its supports were positioned.

Previously, the data acquisition procedure was tested to verify the accuracy and reliability of the measures.

Some recorded relations of pressure-strain circumferential in the upper part of diagrams and the axial in the bottom, for the AISI 316 specimen types A and B, are shown in Figures 9 and 10 . 


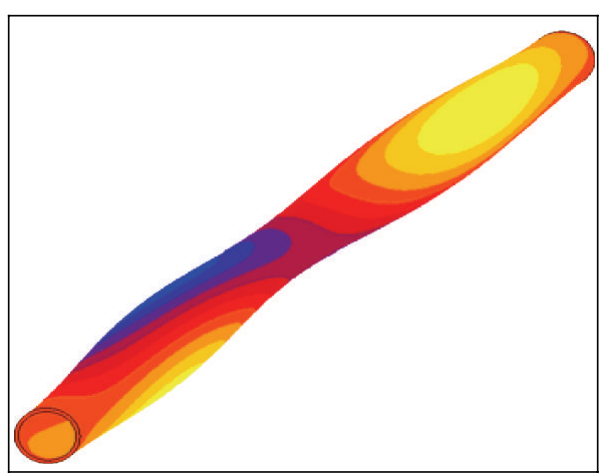

FIgURE 7: Deformed shape for shell with longitudinal weld.
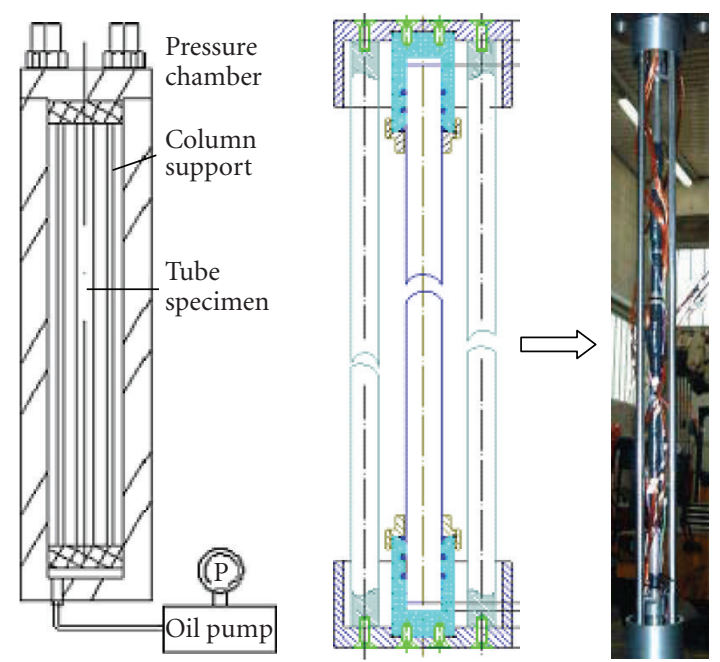

FIGURE 8: Buckling test machine and specimen's support.

In the A tests, the effect of the thickness mismatch had produced an increasing as for the failure pressure (over $50 \mathrm{MPa}$ ) as for the hoop stress in the tube.

The influence of welding is shown in the strain shapes of Figure 10. In this graph, the weld effect is further limited at local area near the weld. In the B tests, the tubes were buckled to a final value of about $40 \mathrm{MPa}$ pressure.

In the above graphs, buckling phenomenon corresponds to the nonlinear part observed, more evident for B tests.

Small deviation from the nominal or perfect geometry results in significant loss of strength of such specimen, where imperfections of just one wall thickness in magnitude can reduce the buckling stress to only one third the classical value for perfect cylinders (according to Koiter 1945).

As pressure approaches bifurcation load, infinitesimally small buckles start to form, which subsequently cause buckling of structure. Circumferential compressive stresses accelerate the development of these prebuckling deformations as is shown in Figure 11(a).

In longitudinally welded cylinder, circumferential stresses reach yield level in tension, therefore, opposite to the effects (circumferential stresses) due to the buckling phenomenon.

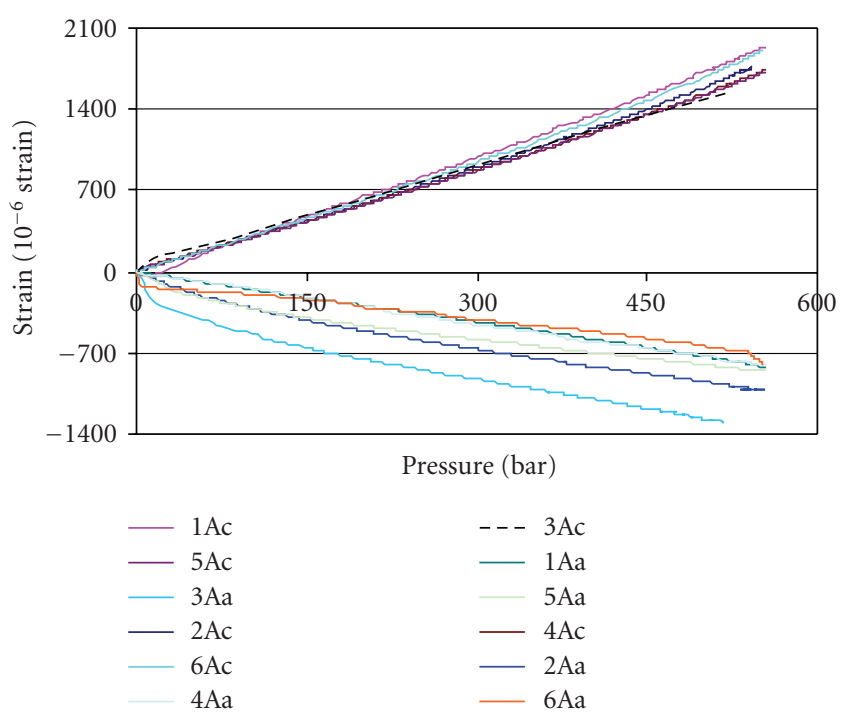

Figure 9: Diagrams of strain versus pressure for A tests.



FIgURE 10: Diagrams of strain versus pressure for B tests.

The stabilizing effect of the tension stresses near the weld is illustrated in Figure 11(b).

With the increase of external pressure loading, the tensile stresses decrease and the compressive stresses farther away from the weld are further increased until the point is reached where the structure buckles [15].

\section{COMPARISON BETWEEN BUCKLING PRESSURE LOADS}

All FEM cases discussed above, for clamped end and external pressure loading, have shown numerical results that indicate a similar behavior and deformation mechanism. However, some significant differences are also observed for the B specimens: the radial expansions of tube and fitting are small, so the rotation and the bending stress near the weld are small. 


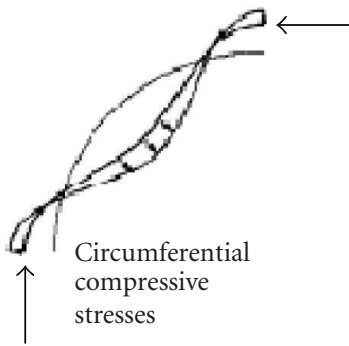

(a)

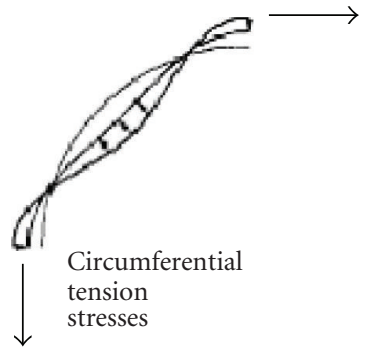

(b)
Figure 11: Effect of circumferential stresses.

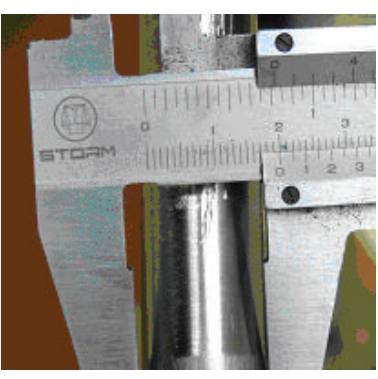

(a)

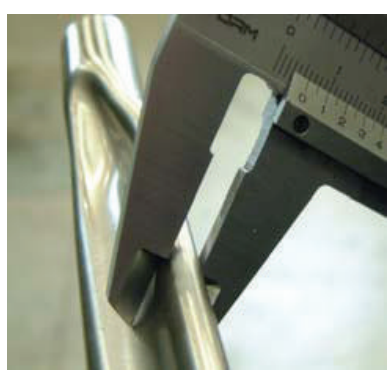

(b)
FIgURE 12: Schematic A and B tubes deformation after buckling.

TABLE 3: Experimental buckling pressure load.

\begin{tabular}{|c|c|c|}
\hline \multirow{3}{*}{ Test $\mathrm{n}^{\circ}$} & \multicolumn{2}{|c|}{ Buckling pressure $(\mathrm{Pa})$} \\
\hline & Type A (welded tubes) & Type B \\
\hline & Experimental & Experimental \\
\hline 1 & $4.48 \mathrm{E}+7$ & $3.72 \mathrm{E}+7$ \\
\hline 2 & $4.74 \mathrm{E}+7$ & $3.80 \mathrm{E}+7$ \\
\hline 3 & $4.81 \mathrm{E}+7$ & $3.90 \mathrm{E}+7$ \\
\hline 4 & $4.74 \mathrm{E}+7$ & $3.71 \mathrm{E}+7$ \\
\hline 5 & $4.95 \mathrm{E}+7$ & $3.63 \mathrm{E}+7$ \\
\hline 6 & $4.57 \mathrm{E}+7$ & $3.71 \mathrm{E}+7$ \\
\hline
\end{tabular}

In Table 3, the main buckling tests results are indicated referring to the tube specimens geometries (length and diameter to thickness ratio equal, resp., to $828 \mathrm{~mm}$ and $D / t=$ 13.3). The experimental data correspond to the pressure value at which the apparent linearity is loss in the test diagram.

The recorded results have been compared with the numerical ones in order to highlight an agreement or discrepancy if any.

A quite good agreement has been obtained between the predicted numerical and experimental buckling pressure values (42 and $38 \mathrm{MPa}$ for seamless A316) in the case of seamless as well as welded tube specimens. It is worth to note that the alteration induced by welding process may increase the local strength of tube (its recorded yielding stress value has been highlighted to be greater than that certified (250 MPa) for austenitic welded steel specimens and might result in an increased strength of tubes themselves.
As already mentioned, from the comparison with the experimental results it is clear that numerical values are higher than the experimental ones, due to other geometrical imperfections not considered. The reason of this discrepancy may be probably due to the other imperfections, which could not be detected on the tube specimens.

The presence of the assumed geometrical imperfections on the shell produces a reduction of about $15 \%$ on buckling pressure respect to that of perfect shell.

Experimental values of collapse, for specimens A, have shown that the geometry discontinuities at the weld were insignificant in the plastic collapse analysis of transition joints.

Schematic picture of collapsed tube, visible in Figures 12(a) and 12(b), shows the buckling modes obtained, for A and $\mathrm{B}$ specimens.

In the latter case, it is shown that buckling mode will always follow the lowest mode without additional constraints.

\section{CONCLUSION}

Noted that the tubes of an integrated PWR steam generator operate at a differential pressure of about $10 \mathrm{MPa}$, it can be shown that the tube can bear fairly high-external pressure levels.

The present work has investigated the plastic collapse failure behavior and considered the effect of thickness mismatch in the weld joint, of ovality and eccentricity.

Most of the analytical approaches proved to be suitable to foresee the collapse loads of the investigated thin tubes, in absence of geometrical imperfections (ovality, eccentricity, and welding), even if with discrepancies larger than the ones characteristic of the numerical approach.

The buckling strength was shown to fluctuate greatly depending on the particular shape of each imperfection and on the interaction between neighboring ones.

The pressure-strain relationship used in the mentioned analyses and showed in the above graphs is crucial to correctly predict the tubes collapse behavior.

The preliminary results show that the numerical approach, implemented with FEM codes, as MSC.MARC, seems able to achieve a good evaluation of the critical load, as a good agreement was obtained between test results and numerical predictions.

Moreover, it has been shown by means of extensive analyses, that this method can accurately predict the collapse behavior of thin tubes, both in linear analyses and under the combined effects of material nonlinearity and geometrical imperfections, respectively.

Numerical analysis has also shown that the thickness mismatch and the strength of welded joint are parameters that control the buckling of welded thin shell.

\section{REFERENCES}

[1] W. T. Koiter, "Elastic stability and post-buckling behaviour," Journal of Structural Engineering, vol. 127, no. 10, pp. 11291136, 2001.

[2] N. Yamaki, Elastic Stability of Cylindrical Shell, chapter 3, North Holland, Amsterdam, The Netherlands, 1984. 
[3] S. P. Timoshenko and J. M. Gere, Theory of Elastic Stability, chapter 10, McGraw-Hil, New York, NY, USA, 1961.

[4] T.-D. Park and S. Kyriakides, "On the collapse of dented cylinders under external pressure," International Journal of Mechanical Sciences, vol. 38, no. 5, pp. 557-578, 1996.

[5] Y. Bai, R. T. Igland, and T. Moan, "Tube collapse under combined external pressure, tension and bending," Marine Structures, vol. 10, no. 5, pp. 389-410, 1997.

[6] M. D. Carelli, L. E. Conway, L. Oriani, et al., "The design and safety features of the IRIS reactor," Nuclear Engineering and Design, vol. 230, no. 1-3, pp. 151-167, 2004.

[7] W. Schneider and A. Brede, "Consistent equivalent geometric imperfections for the numerical buckling strength verification of cylindrical shells under uniform external pressure," ThinWalled Structures, vol. 43, no. 2, pp. 175-188, 2005.

[8] R. K. H. Ng, A. Yousefpour, M. Uyema, and M. N. Ghasemi Nejhad, "Design, analysis, manufacture, and test of shallow water pressure vessels using E-glass/epoxy woven composite material for a semi-autonomous underwater vehicle," Journal of Composite Materials, vol. 36, no. 21, pp. 2443-2478, 2002.

[9] D. O. Brush and B. O. Almroth, Buckling of Bars, Plates and Shells, chapter 5, McGraw-Hill, New York, NY, USA, 1975.

[10] W. Flugge, Stresses in Shell, chapter 7, Springer, Berlin, Germany, 1975.

[11] R. D. Zou and C. G. Foster, "Simple solution for buckling of orthotropic circular cylindrical shells," Thin-Walled Structures, vol. 22, no. 3, pp. 143-158, 1995.

[12] X.-K. Zhu and B. N. Leis, "Plastic collapse assessment method for unequal wall transition joints in transmission pipelines," Journal of Pressure Vessel Technology, vol. 127, no. 4, pp. 449456, 2005.

[13] P. A. Berry, J. M. Rotter, and R. Q. Bridge, "Compression tests on cylinders with circumferential weld depressions," Journal of Engineering Mechanics, vol. 126, no. 4, pp. 405-413, 2000.

[14] X. Wang, J. Xiao, and Y. C. Zhang, "A method solving the buckling problem of thin-walled shell," International Journal of Pressure Vessel and Piping, vol. 81, no. 12, pp. 907-912, 2004.

[15] M. Pircher and R. Q. Bridge, "Buckling of thin-walled silos and tanks under axial load-some new aspects," Journal of Structural Engineering, vol. 127, no. 10, pp. 1129-1136, 2001. 

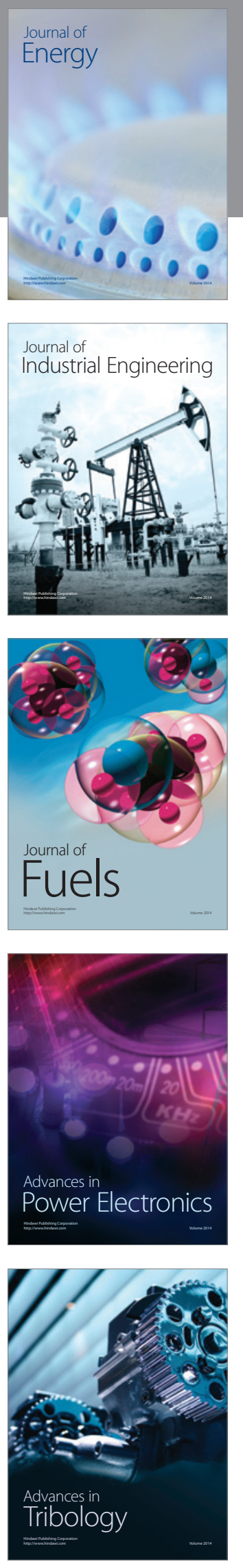
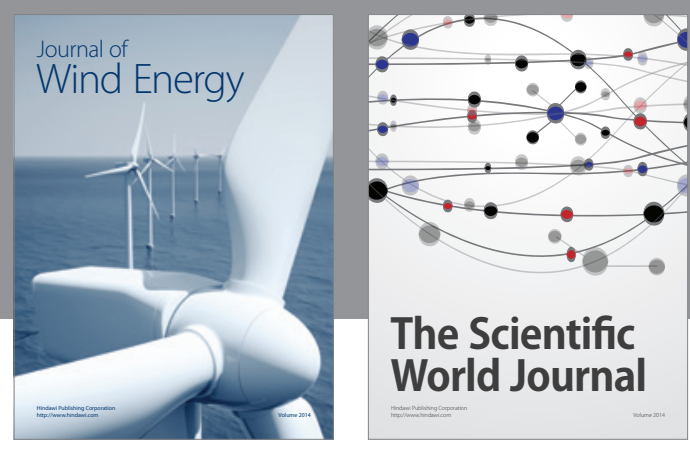

The Scientific World Journal

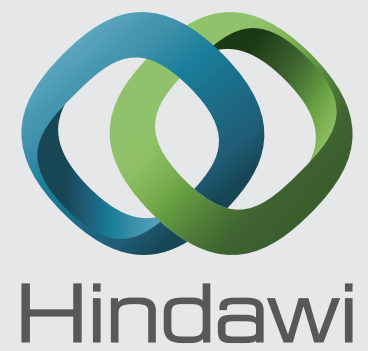

Submit your manuscripts at http://www.hindawi.com




Rotating
Mechinery
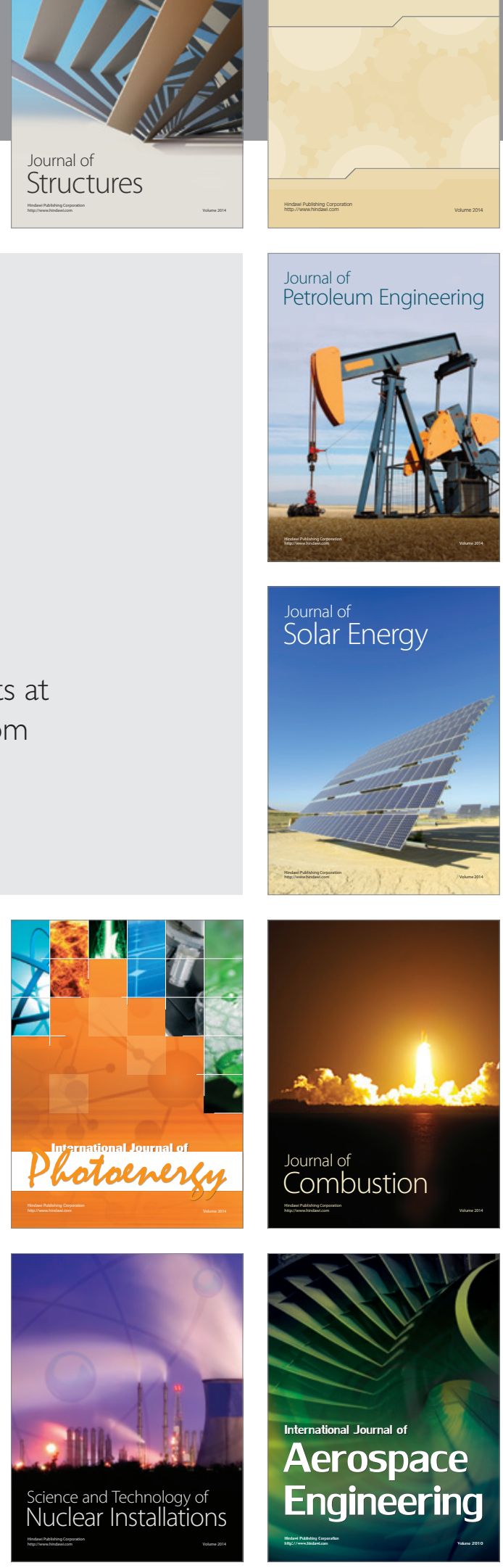